\title{
A novel SLC12A3 homozygous c2039delG mutation in Gitelman syndrome with hypocalcemia
}

\author{
Wenjun Yang, Shaoli Zhao, Yanhong Xie and Zhaohui Mo*
}

\begin{abstract}
Background: Gitelman syndrome (GS) is a rare autosomal recessive renal tubular disease, caused by mutations in the SLC12A3 gene, which encodes the renal thiazide-sensitive $\mathrm{Na} / \mathrm{Cl}$ cotransporter (NCCT) in the distal renal tubule.

Case presentation: A 23-year-old woman was admitted with limb numbness, recurrent tetany and palpitation. Laboratory tests showed hypokalemic alkalosis, hypomagnesemia, hypocalcemia and secondary hyperaldosteronism, as well as hypocalciuria and transient decreased PTH. Next-generation sequencing detected a novel homozygous mutations c.2039delG in the SLC12A3 gene, and her father and children were all heterozygous carriers.

Conclusion: We reported a case of GS with a novel homozygous frame-shift mutation of SLC12A3, and reviewed recent literatures about diagnosis, differential diagnosis and treatments. Hypocalcemia in Gitelman syndrome is rare, and may be related to inhibited PTH secretion induced by hypomagnesemia.
\end{abstract}

Keywords: Gitelman syndrome, SLC12A3 gene mutation, Hypocalcemia

\section{Background}

Gitelman syndrome (GS) is an autosomal recessive disease, characterized by hypokalemic alkalosis, hypomagnesaemia, hypocalciuria, low blood pressure, first described by Gitelman in 1966 [1]. It is caused by mutations in the SLC12A3 gene, which encodes the renal thiazide-sensitive $\mathrm{Na} / \mathrm{Cl}$ cotransporter $(\mathrm{NCCT})$ in the distal renal tubule [2]. Here, we report a case of a new mutation of $S L C 12 A 3$ in an Asian pedigree.

\section{Case presentation}

A 23-year old female was hospitalized due to limb numbness, muscle weakness for one month, recurrent tetany and palpitation for 10 days. She visited the local hospital and was found to have a decreased plasma potassium $(2.24 \mathrm{mmol} / \mathrm{l})$ and calcium $(1.6 \mathrm{mmol} / \mathrm{L})$, while plasma magnesium was unknown because of limited conditions at the hospital. Her condition seem to have improved after treatment with "potassium chloride" and

* Correspondence: easd04mzh@126.com

The Endocrinology Department of the Third Xiangya Hospital, Central South University, Tongzipo Road, Changsha 410013, China "calcium gluconate", however, symptoms recurred after discharge, so she visited our hospital. She denied having any other diseases or taking any medication prior to her visit to the hospital. Her two children and her father were healthy without any similar symptoms. Her mother and her only sister however, had passed away at the age of 30 years old and 1 year old, respectively, with unclear diagnosis. Her parents were from the same town but denied of consanguineous marriage.

Physical examination on admission showed normal vital signs, except for her relatively low blood pressure, which fluctuated between 88 and 108/56-78 $\mathrm{mmHg}$. She had a height of $158 \mathrm{~cm}$ and body weight of $46 \mathrm{~kg}$. The lower limb muscle strength was decreased, accompanied by diminished tendon reflexes. The Trousseau's sign was positive. Other signs of physical examinations were normal.

Laboratory test results are shown in Table 1.

Her thyroid function tests and glucocorticoid level were within the normal range, and autoimmune antibodies were negative, while the $25(\mathrm{OH}) \mathrm{VD} 3$ was $17.08 \mathrm{ng} / \mathrm{mL}$ (reference value: $>20 \mathrm{ng} / \mathrm{ml}$ ). The PTH was $11.2 \mathrm{pg} / \mathrm{ml}$ (reference value: $15-65 \mathrm{pg} / \mathrm{ml}$ ) at the

(c) The Author(s). 2018 Open Access This article is distributed under the terms of the Creative Commons Attribution 4.0 International License (http://creativecommons.org/licenses/by/4.0/), which permits unrestricted use, distribution, and 
Table 1 Clinical tests of the patient

\begin{tabular}{|c|c|c|c|}
\hline Examination items & Test value & & Reference value \\
\hline \multicolumn{4}{|l|}{ Serum biochemicals } \\
\hline Potassium (mmol/L) & 3 & & $3.5-5.3$ \\
\hline Sodium (mmol/L) & 142 & & $137.0-147.0$ \\
\hline Chloride (mmol/L) & 99 & & $99.0-110$ \\
\hline Calcium (mmol/L) & 2.3 & & $2.2-2.7$ \\
\hline Magnesium (mmol/L) & 0.32 & & $0.75-1.02$ \\
\hline Phosphate (mmol/L) & 1.39 & & $0.85-1.51$ \\
\hline $\mathrm{CO} 2 \mathrm{CP}(\mathrm{mmol} / \mathrm{L})$ & 33.5 & & $23-29$ \\
\hline creatine (umol/l) & 43 & & $41-73$ \\
\hline BUN (mmol/l) & 3.15 & & $2.6-7.5$ \\
\hline \multicolumn{4}{|l|}{ Analysis of arterial blood gas } \\
\hline $\mathrm{PH}$ & 7.506 & & $7.35-7.45$ \\
\hline PO2 (mmHg) & 102 & & $90-110$ \\
\hline PCO2 (mmHg) & 35.1 & & $35-45$ \\
\hline $\mathrm{HCO} 3(\mathrm{mmol} / \mathrm{L})$ & 28.9 & & $22-27$ \\
\hline \multicolumn{4}{|l|}{ Urine test } \\
\hline Urine specific gravity & 1.01 & & $1.010-1.025$ \\
\hline $\mathrm{PH}$ & 7.5 & & $4.60-8.00$ \\
\hline \multicolumn{4}{|l|}{ 24-h urine } \\
\hline Potassium (mmol/24 h) & 89 & & $51-100$ \\
\hline Calcium (mmol/24 h) & 0.25 & & $2.5-7.5$ \\
\hline Magnesium (mmol/24 h) & 2.92 & & $1.0-10.5$ \\
\hline Phosphate (mmol/24 h) & 9.44 & & $16-42$ \\
\hline Creatinine (mmol/24 h) & 7.45 & & $7-18$ \\
\hline Calcium/creatinine (mmol/mmol) & 0.03 & & $>0.2$ \\
\hline RAAS system & Before high sodium ${ }^{a}$ & After high sodium & \\
\hline Plasma renin activity (ng /ml.h) & 12.95 & 1.93 & $1.15-2.33$ \\
\hline Angiotensin I (ng /ml) & 16.45 & 3.76 & $0.07-1.5$ \\
\hline Angiotensin II (pg /ml) & 97.68 & 65.62 & $25-60$ \\
\hline Aldosterone (pg / ml) & 225.1 & 152.9 & $30-160$ \\
\hline ARR (ng/dl:ng/ml.h) & 1.74 & 7.92 & $<20$ \\
\hline
\end{tabular}

High sodium load test ${ }^{\mathrm{a}}$ : the patient has intravenous infusion of $0.9 \%$ saline, at a rate of $500 \mathrm{ml} / \mathrm{h}$ for $4 \mathrm{~h}$ between $8: 00$ and $12: 00$ am, and takes blood tests of aldosterone, renin activity, angiotensin before and after infusion. In patients with GS or normal people, plasma aldosterone and renin activity will be inhibited, while in patients with primary aldosteronism, plasma aldosterone levels are not inhibited

local hospital, and returned to the normal range 2 days later. At our hospital the value was $32.66 \mathrm{pg} / \mathrm{ml}$. Her chest X-ray and abdominal ultrasound were normal and the dual-energy $\mathrm{x}$-rays showed osteopenia ( $\mathrm{T}$ value was -1.8 ). Laboratory results suggested hypokalemia, hypomagnesemia, hypocalciuria, metabolic alkalosis, and secondary hyperaldosteronism. These characteristics indicated GS. We also tested the serum electrolytes of the patient's father and children, which showed normal results.

After obtaining informed consent from the patient and family members, genomic DNA was extracted from peripheral blood for SLC12A3 and other related genes of Bartter syndrome whole genome sequencing in the Changsha Kingmed Center for Clinical Laboratory. Genomic DNA was extracted via centrifugal column method, with Qiagen kit. Gene sequencing was performed as referred [3].

We found that the patient was positive for $S L C 12 A 3$ gene homozygous mutation (exon 17: nucleic acid mutation: c.2039delG, amino acid mutation: p.Gly680AspfsTer20). It was a frameshift mutation in exon 17, which began from the glycine in the No.680, mutated into aspartate, and leading to premature termination of NCCT 
protein in the No.700 amino acid (terminator codon TGA). To exclude the possibility that the c2039delG is heterozygous mutation with deletion of the other allele at this locus, we performed copy number variation $(\mathrm{CNV})$ analysis using next-generation sequencing data, the result is shown in Additional file 1: Figure S1, confirming the c.2039delG is bi-allelic homozygous mutation. A heterozygous mutation in the same site was observed in the sequences of the patient's father and her two children. C.2039delG was a novel mutation and has not been reported in SNP databases such as Exome Aggregation Consortium and 1000Genome. We also tested SLC12A1, KCNJ1, CLCNKB, BSND, CLCNKA/CLCNKB related to Bartter syndrome, showing negative results. Pedigree analysis was shown in Fig. 1, and the sequence map is shown in Fig. 2.

\section{Discussion and conclusions}

GS is an inherited renal tubulopathy with a prevalence estimated at one to ten per 40,000 people, and more prevalent in Asia [4]. Diagnosis of GS is based on the clinical symptoms, biochemical abnormalities and genetic test. Common symptoms include salt craving, cramps, muscle weakness, fatigue, etc. Fainting, polyuria, arthralgia, chondrocalcinosis, growth retardation, vertigo, ataxia, tetany, seizure, etc. can also occur [5]. Our patient had numbness, tetany, muscle weakness and palpitations, and low blood pressure. Her symptoms and typical laboratory examinations together corresponded to GS. The criteria for diagnosis of GS is identification of biallelic inactivating mutations in SLC12A3 [5]. To date, more than 400 mutations of SLC12A3 have been identified, including missense/ nonsense mutations, splicing, deletions, insertions, reading frame shifting mutation, etc. Missense mutations are the most frequent. According to a gene analysis of 54 Chinese GS patients by Ruijin Hospital and 42 patients by Peking Union Medical College Hospital, T60 M and D486N are the most common amino acid mutations in Chinese patients $[6,7]$, while IVS9 $+1 \mathrm{G}>\mathrm{T}$ was reported as the most common mutation in a European population [8]. Frame shift mutations were much fewer. In this study, we describe this c.2039delG frame shifting mutation for the first time. The proband has homozygous mutations, and her father and two children are heterogeneous carriers. According to the autosomal recessive inheritance rules, the proband's mother at least carried a heterogeneous mutation.

The differential diagnosis of GS includes diuretic, specifically thiazide abuse and chronic vomiting. Additionally some disorders affecting the kidneys or the gastrointestinal tract can also result in hypokalemic metabolic alkalosis with hyperreninemic secondary aldosteronism. It has been reported that GS-like manifestations could be a rare complication of cisplatin [9]. Autoimmune diseases, Sjögren syndrome, for example, was reported to cause renal tubular disorders, and cause typical features of GS [10-12]. Among various differential diagnosis, classical Bartter syndrome (type III) is the most indistinguishable, though it usually has early onset, and normal plasma magnesium. However, Mutations in the HNF1 $\beta$ gene can mimic the electrolyte abnormalities of GS, approximately $50 \%$ of patients develop hypomagnesemia because of renal magnesium wasting, often accompanied by hypocalciuria [13]. Therefore genetic test is crucial. According to the consensus and guidance from KDIGO, the use of a next generation sequencingbased gene panel to parallel sequence all genes that are relevant in the differential diagnosis of GS is recommended [5]. Besides, GS can be accompanied with other diseases, making differential diagnosis difficult. In some GS cases, thyrotoxicosis coexsits [14]. Although Sjögren

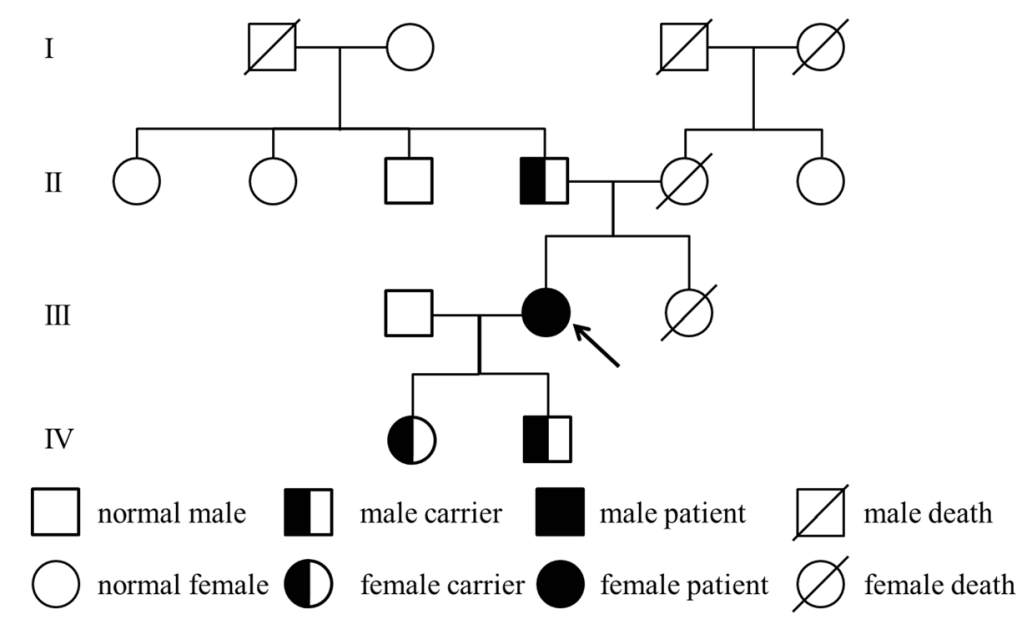

Fig. 1 Pedigree analysis 


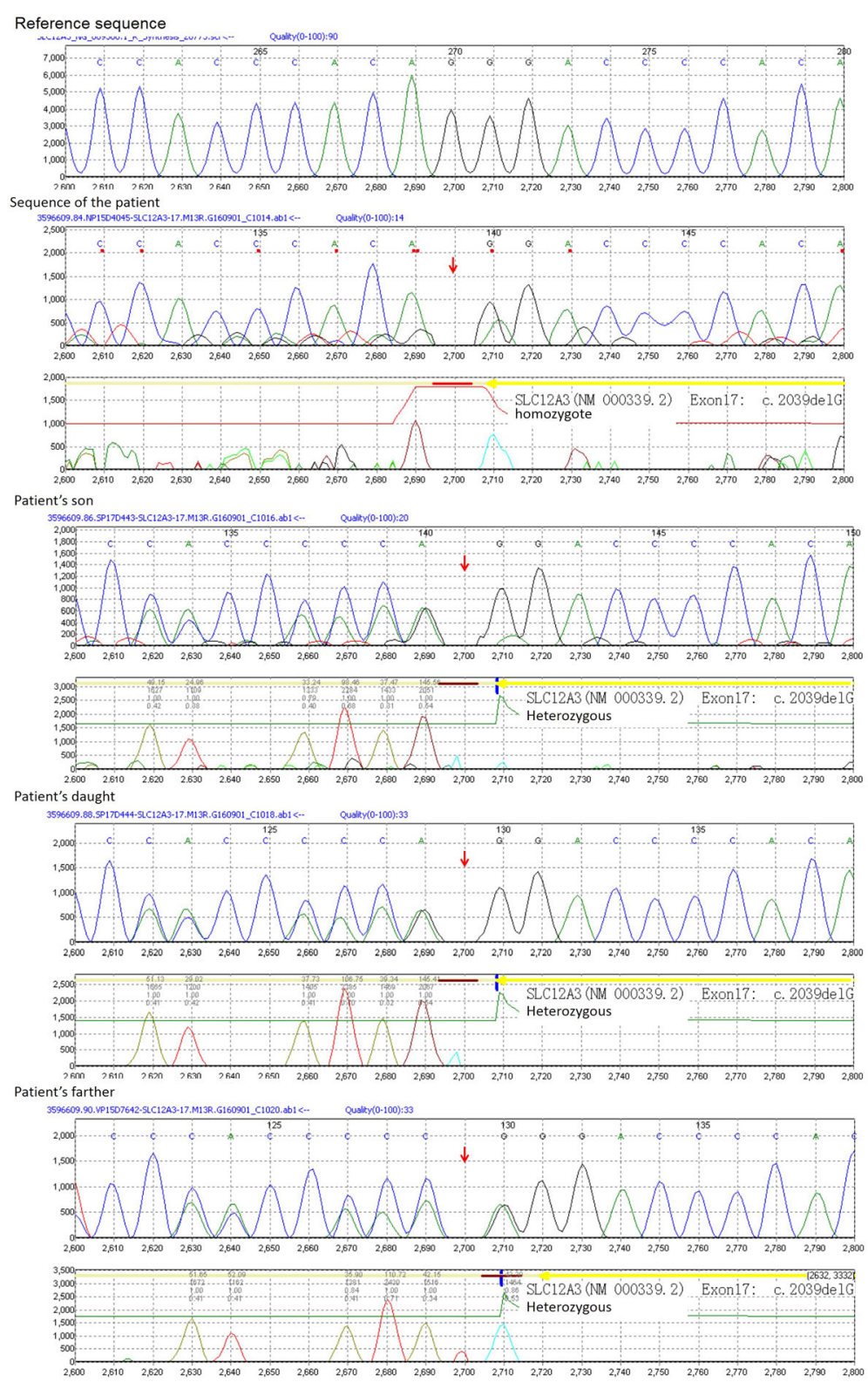

Fig. 2 Sequences of the patient, her children and her father. The above sequence column is the reference sequence, next are the sequence of the patient and her son, daughter, father, respectively. The columns below tested sequences are subtracted results of tested sequence and reference sequence, which show homozygous c.2039delG of the patient and heterozygous mutation of her children and father)

syndrome can cause GS-like symptoms, sometimes they may be comorbidities [15], again making gene sequencing much more important.

Hypocalcemia was rarely reported in GS cases, because calcium excretion through urine is very little. Some explanation to hypocalcemia is that hypomagnesaemia causes defective cyclic AMP generation in the parathyroid glands and in the PTH target organs, leading to impaired secretion of PTH as well as end-organ resistance to PTH [16]. Furthermore PTH could increase serum magnesium by increasing its gastrointestinal absorption and bone resorption [17]. This may explain why our patient had hypocalcemia and transiently decreased PTH. The patient regained normal calcium and PTH status soon. It also reminded us that her tetany was mainly due to hypomagnesemia because it recurred at a normal plasma calcium level.

Treatment of GS is usually managed by a liberal salt $(\mathrm{NaCl})$ intake, together with oral magnesium and potassium supplements. The recommended target for potassium is $3.0 \mathrm{mmol} / \mathrm{l}$ and magnesium $0.6 \mathrm{mmol} / \mathrm{l}$. 
We treated this patient with chloride $(\mathrm{KCl})$, potassium magnesium aspartate. Considering her refractory hypokalemia and recurrent tetany, we added spironolactone and indomethacin, a nonselective inhibitor of cyclooxygenase (COX). Indomethacin is rarely used in GS, because plasma prostaglandin E2 (PGE2) levels in GS are usually normal. But studies found that significantly higher PGE2 and PGE2 metabolites (PGEM) levels in GS patients' urine and PGEM in their plasma. Also, higher urinary PGEM levels indicated more severe clinical manifestations and NCC dysfunction [18]. There was study compared the efficacy and safety of $75 \mathrm{mg}$ indomethacin, $150 \mathrm{mg}$ eplerenone, or $20 \mathrm{mg}$ amiloride added to constant potassium and magnesium supplementation in GS patients, and the result showed each drug increased plasma potassium level by approximately $0.3 \mathrm{mmol} / \mathrm{l}$ [19]. But for long-term treatment, the gastrointestinal, cardiovascular side effects and nephrotoxicity should be considered. After two years follow-up, the patient had a reasonable potassium level of $3.1-3.5 \mathrm{mmol} / \mathrm{l}$, and her symptoms were alleviated, while the plasma magnesium level was still unstable, between 0.4 and 0.8 $\mathrm{mmol} / \mathrm{l}$. It is more difficult to supplement magnesium as magnesium salts frequently cause diarrhoea. Among organic magnesium salts, $\mathrm{MgCl}_{2}$ is preferred, which also compensates the urinary loss of chloride. However, it is unavailable in many places therefore a more readily available therapy should be researched.

In summary, we reported a GS case with hypocalcemia with a novel c.2039delG mutation of SLC12A3 gene with typical clinical symptoms and laboratory findings. Genetic testing makes the diagnosis easier but the cost remains expensive. A better treatment regimen is still worthy to work on.

\section{Additional file}

Additional file 1: Figure S1. The second generation sequencing of the patient, showing c.2039delG homozygous mutation of the patient. (TIF $607 \mathrm{~kb}$ )

\section{Abbreviations}

COX: Cyclooxygenase; GS: Gitelman syndrome; NCCT: Na/Cl cotransporter; PGE2: Prostaglandin E2; PGEM: Prostaglandin E metabolites; PTH: Parathyroid hormone

\section{Acknowledgements}

We thank Changsha Kingmed Center for Clinical Laboratory for their technical assistance, and thank Keshav Nundlall for language edition.

\section{Funding}

This study was supported by grants from the New Xiangya Talent Project of the Third Xiangya Hosipital of Central South University, Number 20150307.

\section{Availability of data and materials}

All data generated or analyzed during this study are included in this published article.

\section{Authors' contributions}

YW designed, drafted and revised the manuscript. ZS and XY participated in the acquisition and interpretation of data. MZ reviewed the manuscript. All authors read and approved the final manuscript.

\section{Ethics approval and consent to participate}

No ethical approval was required for this case report. Written informed consent was obtained from all individual participants or the guardians (if under age of 18) included in the study.

\section{Consent for publication}

Written informed consent was obtained from all individuals who participated to publish the details in this case.

\section{Competing interests}

The authors declare that they have no competing interests.

\section{Publisher's Note}

Springer Nature remains neutral with regard to jurisdictional claims in published maps and institutional affiliations.

Received: 10 March 2018 Accepted: 29 November 2018

Published online: 17 December 2018

\section{References}

1. Gitelman HJ, Graham JB. Welt LG. A new familial disorder characterized by hypokalemia and hypomagnesemia. Trans Assoc Am Phys. 1966;79:221-35.

2. Mastroianni N, Bettinelli A, Bianchetti M, et al. Novel molecular variants of the Na-cl cotransporter gene are responsible for Gitelman syndrome. Am J. Hum Genet. 1996;59(5):1019-26.

3. Zhang L, Zhang J, Yang J, et al. PriVar: a toolkit for prioritizing SNVs and indels from next-generation sequencing data. Bioinformatics. 2013; 29(1):124-5

4. Parmar MS, Bhimji SS. Gitelman Syndrome; 2017.

5. Blanchard A, Bockenhauer D, Bolignano D, et al. Gitelman syndrome: consensus and guidance from a kidney disease: improving global outcomes (KDIGO) controversies conference. Kidney Int. 2017;91(1):24-33.

6. Ma J, Ren $H$, Lin L, et al. Genetic features of Chinese patients with Gitelman syndrome: sixteen novel SLC12A3 mutations identified in a new cohort. Am Jephrol. 2016;44(2):113-21.

7. Wang F, Shi C, Cui Y, Li C, Tong A. Mutation profile and treatment of Gitelman syndrome in Chinese patients. Clin Exp Nephrol. 2017;21 (2):293-9.

8. Bouwer ST, Coto E, Santos F, et al. The Gitelman syndrome mutation, IVS9 +1G\&gt;T, is common across Europe. Kidney Int. 2007;72(7):898.

9. Panichpisal K, Angulo-Pernett F, Selhi S, Nugent KM. Gitelman-like syndrome after cisplatin therapy: a case report and literature review. BMC Nephrol. 2006; 7:10.

10. Gu X, Su Z, Chen M, Xu Y, Wang Y. Acquired Gitelman syndrome in a primary Sjogren syndrome patient with a SLC12A3 heterozygous mutation: a case report and literature review. Nephrology (Carlton). 2017;22(8):652-5

11. Hinschberger $\mathrm{O}$, Martzolff $\mathrm{L}$, loannou G, et al. Acquired Gitelman syndrome associated with Sjogren's syndrome and scleroderma. Rev Med Interne. 2011:32(8):e96-8.

12. Kim YK, Song HC, Kim WY, et al. Acquired Gitelman syndrome in a patient with primary Sjogren syndrome. Am J Kidney Dis. 2008:52(6):1163-7.

13. Adalat $\mathrm{S}$, Woolf $A \mathrm{~S}$, Johnstone KA, et al. HNF1B mutations associate with hypomagnesemia and renal magnesium wasting. J Am Soc Nephrol. 2009; 20(5):1123-31.

14. Molin C, Trevisol DJ. Persistent severe hypokalemia: Gitelman syndrome and differential diagnosis. J Bras Nefrol. 2017;39(3):337-40

15. Mishima E, Mori T, Sohara E, et al. Inherited, not acquired, Gitelman syndrome in a patient with Sjogren's syndrome: importance of genetic testing to distinguish the two forms. CEN Case Rep. 2017;6(2):180-4

16. Rude RK, Oldham SB, Singer FR. Functional hypoparathyroidism and parathyroid hormone end-organ resistance in human magnesium deficiency. Clin Endocrinol. 1976;5(3):209-24.

17. Sanda S, Schlingmann KP, Newfield RS. Autosomal dominant hypoparathyroidism with severe hypomagnesemia and hypocalcemia, successfully treated with recombinant PTH and continuous 
subcutaneous magnesium infusion. J Pediatr Endocrinol Metab. 2008; 21(4):385-91.

18. Peng $X$, Jiang $L$, Chen $C$, et al. Increased urinary prostaglandin E2 metabolite: a potential therapeutic target of Gitelman syndrome. PLoS One. 2017;12(7):e0180811.

19. Blanchard A, Vargas-Poussou R, Vallet $M$, et al. Indomethacin, amiloride, or eplerenone for treating hypokalemia in Gitelman syndrome. J Am Soc Nephrol. 2015;26(2):468-75

Ready to submit your research? Choose BMC and benefit from:

- fast, convenient online submission

- thorough peer review by experienced researchers in your field

- rapid publication on acceptance

- support for research data, including large and complex data types

- gold Open Access which fosters wider collaboration and increased citations

- maximum visibility for your research: over $100 \mathrm{M}$ website views per year

At BMC, research is always in progress.

Learn more biomedcentral.com/submissions 